\title{
A case of recurrence of adult-onset Still's disease in the third trimester: a case report and literature review
}

\author{
Satoshi Hosoya ${ }^{1 *}$ (D, Miyuki Sadatsuki ${ }^{1}$, Shinji Izuka ${ }^{2}$, Hiroyuki Yamashita ${ }^{2}$ and Hajime Oishi ${ }^{1}$
}

\begin{abstract}
Background: Adult-onset Still's disease (AOSD) is a self-inflammatory disease showing macrophage and neutrophil activation by inflammatory cytokines such as TNF-a, IL-6, and IL-18. Although some cases with the flare of AOSD during pregnancy have been reported, most had flares in the first or second trimester and few had flares in the third trimester. In this report, we present the case of a patient with recurrent flare of AOSD in the third trimester and discuss the management of AOSD in the third trimester with the review of previous literatures.

Case presentation: A 38-year-old woman in complete AOSD remission without medication presented with impaired liver function, low platelet count, mild fever, abdominal pain, splenomegaly, and elevated ferritin and IL-18 levels at 30 gestational weeks. Although the laboratory data and physical examination finding suggested HELLP syndrome or acute fatty liver of pregnancy and we considered the termination of her pregnancy, her fetus was in a reactive status. Considering her fetal status, some specific findings of AOSD, and her AOSD history, we and rheumatologists diagnosed her with AOSD recurrence and started systemic steroid therapy. In her clinical course, three flares of AOSD occurred, twice in the third trimester and once in postpartum; twice systemic steroid pulse therapies were then needed. Ultimately, a healthy infant was delivered transvaginally at 36 gestational weeks spontaneously.

Conclusions: Specific findings of the flare of AOSD such as fever, splenomegaly, elevated ferritin and IL-18 levels, and fetal status could be useful findings for differentiation from HELLP syndrome and AFLP in the third trimester. With the careful management supported by rheumatologists, patients complicated with the flare of AOSD may continue their pregnancy longer than we expected.
\end{abstract}

Keywords: Adult-onset Still's disease, HELLP syndrome, IL-18, Third trimester, Pregnancy

\section{Background}

Adult-onset Still's disease (AOSD) is a self-inflammatory disease exhibiting macrophage and neutrophil activation by inflammatory cytokines such as tumor necrosis factor- $\alpha$ (TNF- $\alpha$ ), interleukin-6 (IL-6), and interleukin18 (IL-18). Its incidence is $1.6-4.0$ in $1,000,000$ people per year [1]. AOSD more likely occurs in women,

* Correspondence: shosoya@hosp.ncgm.go.jp

1 Department of Obstetrics and Gynecology, National Center for Global Health and Medicine, 1-21-1, Toyama, Shinjuku-ku, Tokyo 162-8655, Japan Full list of author information is available at the end of the article affecting 50 to $70 \%$, than in men [1]. It mostly affects young adults (median age at diagnosis: 36 years) [1], indicating the reproductive ages in women. The Yamaguchi criteria [2] are commonly used to diagnose AOSD because they suggest major symptoms and laboratory findings of AOSD; common manifestations are remittent fever over $39^{\circ} \mathrm{C}$ lasting more than a week, arthralgia or arthritis, typical rash, high white blood cell count, elevated liver enzymes, and splenomegaly (Table 1). In addition, some AOSD cases manifest abdominal pain and nausea [1]. If findings such as elevated liver enzyme

(c) The Author(s). 2021 Open Access This article is licensed under a Creative Commons Attribution 4.0 International License, which permits use, sharing, adaptation, distribution and reproduction in any medium or format, as long as you give appropriate credit to the original author(s) and the source, provide a link to the Creative Commons licence, and indicate if changes were made. The images or other third party material in this article are included in the article's Creative Commons licence, unless indicated otherwise in a credit line to the material. If material is not included in the article's Creative Commons licence and your intended use is not permitted by statutory regulation or exceeds the permitted use, you will need to obtain permission directly from the copyright holder. To view a copy of this licence, visit http://creativecommons.org/licenses/by/4.0/ The Creative Commons Public Domain Dedication waiver (http://creativecommons.org/publicdomain/zero/1.0/) applies to the data made available in this article, unless otherwise stated in a credit line to the data. 
and abdominal pain happen during pregnancy, AOSD may be misinterpreted as hemolysis, elevated liver enzymes and low platelet count (HELLP) syndrome and acute fatty liver of pregnancy (AFLP). Currently, although the association between the disease onset of AOSD and pregnancy has already been widely investigated $[3,4]$, such relationship remains unclear. Moreover, reported cases of AOSD flares at third trimester are few, and the management and features of AOSD, which has similar features to HELLP syndrome and AFLP, at the third trimester have not been reported yet. Herein, we report a rare case of a pregnant woman with AOSD recurrence at her 30 gestational weeks and reviewed the previous reports on the flares of AOSD related to pregnancy. Written informed consent for the publication of this report was obtained from the patient.

\section{Case presentation}

A 38-year-old primigravida with well-controlled gestational diabetes mellitus (GDM) was introduced from her home doctor to our hospital, presenting with mild fever, liver dysfunction, elevated ferritin, low platelet count, and proteinuria at 30 weeks and 5 days of gestation. She was diagnosed with AOSD 6 years ago in our hospital based on typical symptoms, including fever, malaise, cervical lymphadenopathy, rash, liver disfunction, and high serum ferritin levels. Although the rheumatologists performed biopsies of her bone marrow and lymph node, the results of these examination were normal and the possibility of other hematologic diseases was denied. After the combination treatment with systemic steroid and tocilizumab administration, she was in complete clinical remission without medication at conception. Upon arrival, her body temperature, blood pressure, and heart rate were $37.7^{\circ} \mathrm{C}, 101 / 63 \mathrm{mmHg}$, and 103 beats/ min. In systemic physical examinations, no abnormalities were found. The laboratory findings at arrival are presented in Table 2; The results indicated liver dysfunction, low platelet, and elevated IL-18 and aldolase levels. No apparent coagulopathy findings were observed. Basic infectious disease tests including Epstein-Barr virus and cytomegalovirus were all negative. Nonstress test and fetal sonography revealed perfect biophysical profile scoring of her fetus, mild polyhydramnios (maximum vertical pocket of amnion: $8.3 \mathrm{~cm}$ ), and an estimated fetal body weight (EFBW) of $1663 \mathrm{~g}$ (+ 0.8 standard deviation [SD]). However, splenomegaly was detected by additional abdominal sonography. Although HELLP syndrome or AFLP was suspected upon admission according to liver dysfunction and low platelet count at third trimester and termination of pregnancy could be possible, her clinical course and examination results did not match well to Sibai's criteria for HELLP syndrome [5] and Swansea's criteria for AFLP [6]. Moreover, her general condition and fetal status did not require urgent intervention. Considering the findings such as mild fever, elevated ferritin level, high level of IL-18, splenomegaly, and good fetal status, she was ultimately diagnosed with recurrence flare of AOSD by us and some rheumatologists. Thus, systemic steroid pulse therapy (first dose: $250 \mathrm{mg}$ of methylprednisolone [mPSL] for 3 days) was initiated and switched to oral prednisolone (PSL) thereafter. Additionally, the patient was carefully followed up by frequent laboratory tests and transabdominal fetal sonography. Figure 1 illustrates her clinical course after hospitalization at 30 gestational weeks. Clinical AOSD findings such as fever, liver dysfunction, and high ferritin level were well controlled for 3 weeks after the initiation of systemic steroid therapy; hence, the oral PSL dosage was gradually reduced. However, another steroid pulse therapy was needed for the second flare of AOSD that happened at her 33 gestational weeks with

Table 1 Yamaguchi criteria for the diagnosis of adult-onset Still's disease [2]

\begin{tabular}{ll}
\hline Major criteria & Fever $\geq 39^{\circ} \mathrm{C}$ lasting $\geq 1$ week \\
& Arthralgia or arthritis lasting $\geq 2$ weeks \\
Minor criteria & Typical nonpruritic salmon-colored rash \\
& Leukocytosis $\geq 10,000 / \mu$ with granulocytes $\geq 80 \%$ \\
& Sore throat \\
Lymphadenopathy & Splenomegaly \\
Exclusion criteria & Abnormal liver function tests \\
& Negative tests for antinuclear antibody and rheumatoid factor \\
& Infection \\
& Malignancy \\
Other rheumatic disease (vasculitis)
\end{tabular}


Table 2 Laboratory findings

\begin{tabular}{lll}
\hline & Value & Reference intervals, unit \\
\hline T-Bil & 0.7 & $0.4-1.5, \mathrm{mg} / \mathrm{dl}$ \\
AST & 491 & $13-30, \mathrm{U} / \mathrm{L}$ \\
ALT & 438 & $7-23, \mathrm{U} / \mathrm{L}$ \\
LDH & 653 & $124-222, \mathrm{U} / \mathrm{L}$ \\
Y-GTP & 10 & $9-32, \mathrm{U} / \mathrm{L}$ \\
BUN & 6.4 & $8.0-20.0, \mathrm{mg} / \mathrm{dl}$ \\
Cre & 0.58 & $0.46-0.79, \mathrm{mg} / \mathrm{dl}$ \\
BS & 84 & $80-110, \mathrm{mg} / \mathrm{dl}$ \\
UA & 3.3 & $2.6-7.0, \mathrm{mg} / \mathrm{dl}$ \\
CRP & 1.81 & $0.00-0.14, \mathrm{mg} / \mathrm{dl}$ \\
TG & 163 & $30-149, \mathrm{mg} / \mathrm{dl}$ \\
Ferritin & 281 & $5-157, \mathrm{ng} / \mathrm{ml}$ \\
WBC & 2980 & $3300-8600, / \mu l$ \\
RBC & 3.93 & $3.86-4.92, \times 10^{6} / \mu l$ \\
Hb & 10.7 & $11.6-14.8, \mathrm{~g} / \mathrm{dl}$ \\
Ht & 32.5 & $35.1-44.4, \%$ \\
Plt & 108 & $158-348, \times 10^{3} / \mu \mathrm{l}$ \\
PT-INR & 0.89 & $0.90-1.10$ \\
APTT & 33 & $25-35, \mathrm{~seconds}$ \\
Fib & 407 & $200-400, \mathrm{mg} / \mathrm{dl}$ \\
AT III & $96-130, \%$ \\
Urinary protein & 0.33 & $0.02-0.12, \mathrm{~g} / \mathrm{day}$ \\
IL-18 & 175,116 & $2.5-7.5, \mathrm{U} / \mathrm{L}$ \\
Aldolase & 30.6 & \\
\hline & & \\
\hline
\end{tabular}

elevated liver enzymes and rash on her trunk. In her clinical course, although with maintained uneventful fetal status, the growth of the fetus had been gradually restricted, resulting in intrauterine growth restriction (IUGR). At 36 weeks and 0 days of gestation, she had irregular uterine contractions without apparent infectious findings, and preterm premature rupture of membrane (pPROM). Finally, she spontaneously delivered a female infant transvaginally at 36 weeks and 3 days of gestation. Her infant had a low birth weight $(2440 \mathrm{~g}$ ) but was very healthy; the Apgar score was 9/10, and $\mathrm{pH}$ of the umbilical artery was 7.312. Moreover, no abnormal findings of the amniotic fluid at delivery and no pathological features in her placenta and umbilical cord were found. At 12 days postpartum, she had elevated ferritin levels and extremely low platelet count, indicating the third AOSD flare by a rheumatologist; thus, the dosage of oral PSL was increased and maintained for months. During her follow-up checkup as an outpatient by rheumatologists at 1 year postpartum, her C-reactive protein (CRP) and ferritin levels were within the reference range, and her platelet count gradually increased, indicating a wellcontrolled AOSD.

\section{Discussion and conclusions}

The flare of AOSD in pregnancy was first reported in 1980 by Stein et al. [7]. Currently, nearly 30 reports about AOSD associated with pregnancy have been published [3, 4, 7-32]. Hence, we reviewed the cases of AOSD complications during pregnancy [3, 4, 7-32]. A total of 53 flares in 47 pregnant women, including our case, have been recorded. The clinical course of AOSD during pregnancy consists of three types: first-onset type, which refers to the first onset of AOSD related to pregnancy $[3,4,7,8,11,12,14,17-25,28-30,32]$, recurrent-flare type, which refers to a recurrent flare related to pregnancy with previous AOSD diagnosis $[4,7$, $9,13,14,16,25,31]$, and no-flare type, which is only a complication with no flare related to pregnancy $[4,9,10$, $14,15,17,26,27]$. In the literature review, the cases were divided into these three types shown in Table 3 and our case belongs to the recurrent-flare type.

The median age of patients at pregnancy was almost 30 years (median [interquartile range (IQR)]: 29 [25-33], 31 [29-34], and 27 [26-30] for the first-onset, recurrent-flare, and no-flare types, respectively), indicating that women with AOSD during pregnancy were younger than the general population at first diagnosis [1]. Regarding parity, AOSD flare mainly happens among primigravida patients, with the recurrent-flare type obtaining the highest rate (83.3\%), although all patients in this type are in clinical remission at conception $[4,7$, $9,13,14,16,25,31]$. Our case was also in clinical remission and did not require any medication at conception.

Most likely, the AOSD flare occurred until second trimester and at postpartum, with limited reports of flare at third trimester; the first-onset type was found only in two cases [21, 24] and the recurrent-flare type in one case, which is our case. Although AOSD flare occurring at third trimester is extremely rare, the clinical symptoms of AOSD are similar to those of HELLP syndrome and AFLP, suggesting that close attention to perinatal management is crucial. Generally, the Yamaguchi criteria [2] is adopted for the diagnosing AOSD (Table 1). However, we needed to assess AOSD recurrence in a comprehensive way by considering the clinical features and laboratory findings because no criteria for the diagnosis of AOSD recurrence are currently available. In fact, the review showed that most of the major symptoms of AOSD detected in the recurrent-flare type are relatively fewer than in the first-onset type. In addition, the major symptoms and findings of AOSD are elevated liver enzyme, leukocytosis, and sometimes abdominal pain or nausea, which are difficult to distinguish from HELLP syndrome or AFLP, particularly in cases with flare occurring at third trimester. Elevated ferritin [2] and IL-18 [33], which are reportedly biomarkers of AOSD activity, are considered better diagnostic markers than any other 


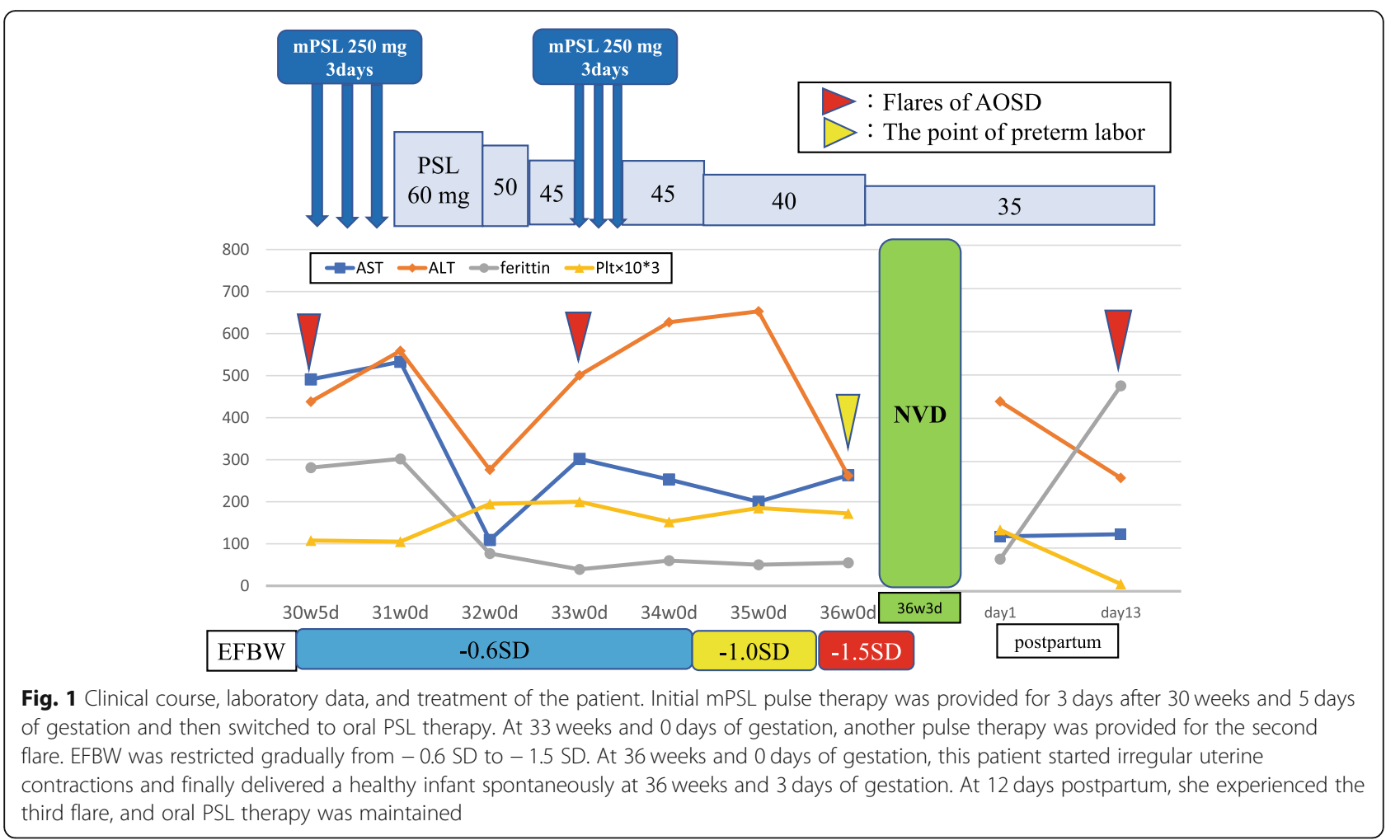

markers. Specific AOSD features such as fever, splenomegaly, and typical rash can support the possibility of AOSD. Izuka et al. recently reported that elevated serum aldolase can be a useful biomarker of AOSD [34]. In our case, the serum aldolase level was high $(30.6 \mathrm{U} / \mathrm{L})$, which supported the diagnosis of recurrent AOSD flare. Finally, we and some rheumatologists comprehensively diagnosed the patient with AOSD recurrence flare in consideration of the AOSD findings such as elevated ferritin, IL-18, and aldolase levels, splenomegaly, and uneventful fetal status.

AOSD treatments generally include PSL $/ \mathrm{mPSL}$, nonsteroidal anti-inflammatory agents (NSAIDs) and in more severe cases, methotrexate, anakinra (interleukin-1 [IL-1] inhibitor), intravenous immune globulin (IVIg), cyclosporine, or tacrolimus. However, selecting the appropriate medication for pregnant patients entails some limitations. Jamilloux $\mathrm{Y}$ et al. recommended corticosteroids as the first treatment choice, and IVIg and IL-1 inhibitor as the second treatment choice for AOSD [35]. Our review also showed that corticosteroid was mainly used, followed by IL-1 inhibitor and IVIg. In Japan, where most of the IL-1 antagonists have not yet been approved, tacrolimus may be a reasonable second choice for severe AOSD flare in pregnancy, and some successful management cases reported to have used this medication during pregnancy $[11,23]$. In our case, twice mPSL pulse therapy followed by oral PSL was chosen; consequently, pregnancy was maintained until 36 gestational weeks.

In almost one-third of cases in both the first-onset and recurrent-flare types, the main obstetrical complication was preterm birth. Some reports showed that other autoimmune diseases or autoinflammatory diseases, such as systemic lupus erythematosus and rheumatoid arthritis, occurring during pregnancy are risk factors for preterm birth, and maternal disease activity contributes to the increased risk of preterm delivery [36-38]. Furthermore, long-term steroidal use is another risk factor for preterm birth [37, 38]. Our review results showed that the incidence of preterm delivery in both the first-onset and recurrent-flare types of AOSD was almost twice higher than that in the no-flare type. Therefore, the high disease activity of AOSD and long-term use of systemic steroids may be possible reasons for the high incidence of preterm delivery in patients with AOSD. Our case also delivered prematurely, with high disease activity and long-term systemic steroid use including twice steroid pulse therapies. Hemophagocytic lymphohistiocytosis $(\mathrm{HLH})$ is also a severe and crucial complication of AOSD. HLH was diagnosed in some cases having the first-onset and recurrent-flare types and in neonatal cases delivered from mothers with AOSD, even in clinical remission. Meanwhile, we believe that in general, the 
Table 3 Review of pregnancy cases with adult onset Still's disease classified into three types

Total: 47 pregnant women and 53 pregnancies

\begin{tabular}{|c|c|c|c|}
\hline & First onset (Number $=26$ ) & Recurrent flare (Number $=13$ ) & No flare (Number $=14$ ) \\
\hline Age at pregnancy (year), Median [IQR] & 29 [25-33] (1 unknown case) & 31 [29-34] & 27 [26-30] (1 unknown case) \\
\hline \multicolumn{4}{|l|}{ Parity, \% } \\
\hline Primigravida & $50(8 / 16)$ & $80(8 / 10)$ & $69.2(9 / 13)$ \\
\hline Multigravida & $50(8 / 16)$ & $20(2 / 10)$ & $30.8(4 / 13)$ \\
\hline Unknown, number & 10 & 3 & 1 \\
\hline \multicolumn{4}{|l|}{ Timing of flare, \% } \\
\hline 1st trimester & $24(6 / 25)$ & $23.1(3 / 13)$ & - \\
\hline 2nd trimester & $52(13 / 25)$ & $38.5(5 / 13)$ & - \\
\hline 3rd trimester & $8(2 / 25)$ & $7.7(1 / 13)$ & - \\
\hline Postpartum & $16(4 / 25)$ & $30.8(4 / 13)$ & - \\
\hline Unknown, number & 1 & 0 & - \\
\hline \multicolumn{4}{|l|}{ Major symptoms and complications, \% } \\
\hline Fever & $95.7(22 / 23)$ & $70(7 / 10)$ & - \\
\hline Arthralgia, Arthritis & $91.3(21 / 23)$ & $60(6 / 10)$ & - \\
\hline Erythema, Rash & $78.3(18 / 23)$ & $50(5 / 10)$ & - \\
\hline Sore throat & $65.2(15 / 23)$ & $30(3 / 10)$ & - \\
\hline Lymphadenopathy & $60.9(14 / 23)$ & $10(1 / 10)$ & - \\
\hline Hepatomegaly, Liver dysfunction & $34.8(8 / 23)$ & $30(3 / 10)$ & - \\
\hline Splenomegaly & $34.8(8 / 23)$ & $10(1 / 10)$ & - \\
\hline $\mathrm{HLH}$ & $8.7(2 / 23)$ & $10(1 / 10)$ & - \\
\hline Unknown, number & 3 & 3 & - \\
\hline \multicolumn{4}{|l|}{ Major treatment, \% } \\
\hline Corticosteroid & $82.6(19 / 23)$ & $69.2(9 / 13)$ & $28.6(4 / 14)$ \\
\hline Anakinra & $13.0(3 / 23)$ & $7.7(1 / 13)$ & $28.6(4 / 14)$ \\
\hline IVlg & $17.4(4 / 23)$ & $7.7(1 / 13)$ & $7.1(1 / 14)$ \\
\hline NSAIDs & $21.7(5 / 23)$ & $7.7(1 / 13)$ & $14.3(2 / 14)$ \\
\hline $\mathrm{HCQ}$ & $4.3(1 / 23)$ & $15.4(2 / 13)$ & $7.1(1 / 14)$ \\
\hline No medication & - & - & $57.1(8 / 14)$ \\
\hline Unknown, number & 3 & 0 & 0 \\
\hline \multicolumn{4}{|l|}{ Delivery, \% } \\
\hline Transvaginal & $66.7(12 / 18)$ & $50(4 / 8)$ & $62.5(5 / 8)$ \\
\hline Cesarean section & $22.2(4 / 18)$ & $50(4 / 8)$ & $25(2 / 8)$ \\
\hline Abortion & $11.1(2 / 18)$ & $0(0 / 8)$ & $12.5(1 / 8)$ \\
\hline Unknown, number & 8 & 5 & 6 \\
\hline \multicolumn{4}{|c|}{ Major obstetrical and perinatal complications, \% } \\
\hline Preterm birth & $32(8 / 25)$ & $33.3(4 / 12)$ & $16.7(2 / 12)$ \\
\hline IUGR & $8(2 / 25)$ & $41.7(5 / 12)$ & $8.3(1 / 12)$ \\
\hline PPROM & $12(3 / 25)$ & $8.3(1 / 12)$ & $8.3(1 / 12)$ \\
\hline No major complication & $48(12 / 25)$ & $41.7(5 / 12)$ & $50(6 / 12)$ \\
\hline Others, number & $\begin{array}{l}2 \text { for OHD, } 1 \text { for neonatal } \mathrm{HLH}, 1 \text { for } \\
\text { preeclampsia, and } 1 \text { for neonatal } \\
\text { death for IRDS }\end{array}$ & 1 for GDM, and 1 for OHD & $\begin{array}{l}1 \text { for neonatal HLH, } 1 \text { for GDM, } \\
\text { and } 1 \text { for HDP }\end{array}$ \\
\hline Unknown, number & 1 & 1 & 2 \\
\hline
\end{tabular}


overall severity of AOSD during pregnancy may be better than the HELLP syndrome and AFLP. In fact, lethal complication was only found in one case wherein a premature fetus died at 28 weeks old because of infantile respiratory distress syndrome (IRDS) in the first-onset type, as reported by Green et al. in 1982 [8]. Therefore, with the cooperation of rheumatologists and pediatricians, pregnant patients with AOSD can maintain their pregnancy by paying special attention to prematurity, fetal growth, and $\mathrm{HLH}$, even if the case is in clinical remission.

The relationship of pathogenesis between AOSD and pregnancy remains unclear. Ida $\mathrm{A}$ et al. reported that serum IL-18 levels were significantly elevated in pregnant women from the first trimester until the onset of labor than in nonpregnant women [39]. They noticed further increment of serum IL-18 levels after labor, lasting until at least the third day of postpartum. This result parallels the clinical feature of AOSD in pregnancy, that is, AOSD flares are likely to happen in the first/second trimester and postpartum. Considering that our case had also prominently high IL-18 levels, IL-18 elevation may cause the flare of AOSD during pregnancy, suggesting that pregnancy may be a risk factor of AOSD. Therefore, the serum IL-18 levels as a follow-up during pregnancy may be a useful predictive and diagnostic marker of AOSD flare; however, further investigations are required.

From the abovementioned consideration, patients with AOSD can be pregnant and continue pregnancy safely while under treatment, considering that the prognosis of pregnant women with AOSD and their fetuses is favorable in previous cases. Furthermore, for a safer pregnancy in patients complicated with AOSD, we, as obstetricians, need tight cooperation with rheumatologists and pediatricians for the sufficient control of AOSD activity and perinatal care and should provide enough explanation to patients on the risks of flares during pregnancy. Moreover, we conduct frequent laboratory tests and careful follow-up in preparation for flares, premature birth, and HLH. If the flare happens at third trimester, as in our case, we need to differentiate AOSD from HELLP syndrome and AFLP because of the similarity of laboratory data and physical findings. Fever, splenomegaly, elevated ferritin and IL-18 levels, and fetal status could be useful findings for the differentiation from HELLP syndrome and AFLP.

To our knowledge, this report is the first to present the recurrent flare of AOSD during pregnancy at third trimester. However, we need to further investigate on the proper management of pregnant women with AOSD.

\section{Abbreviations}

AOSD: Adult-onset Still's disease; TNF-a: Tumor necrosis factor-a; IL6: Interleukin-6; IL-18: Interleukin-18; HELLP: Hemolysis, elevated liver enzymes and low platelet count; AFLP: Acute fatty liver of pregnancy; GDM: Gestational diabetes mellitus; EFBW: Estimated fetal body weight;
SD: Standard deviation; mPSL: Methylprednisolone; PSL: Prednisolone; IUGR: Intrauterine growth restriction; PPROM: Preterm premature rupture of membrane; CRP: C-reactive protein; IQR: Interquartile range; NSAI Ds: Nonsteroidal anti-inflammatory agents; IL-1: Interleukin-1; IVlg: Intravenous immune globulin; HLH: Hemophagocytic lymphohistiocytosis; IRDS: Infantile respiratory distress syndrome; NVD: Normal vaginal delivery; T-Bil: Total bilirubin; AST: Aspartate aminotransferase; ALT: Alanine aminotransferase; LDH: Lactate dehydrogenase; $\gamma$-GTP: $\gamma$-glutamyl transpeptidase; BUN: Blood urea nitrogen; Cre: Creatinine; BS: Blood sugar; TG: Triglyceride; WBC: White blood cell; RBC: Red blood cell; Hb: Hemoglobin; Ht: Hematocrit; Plt: Platelet; PTINR: Prothrombin-time international normalized ratio; APTT: Activated partial thromboplastin time; Fib: Fibrinogen; AT III: Antithrombin III;

HCQ: Hydroxychloroquine; OHD: Oligohydramnios; HDP: Hypertensive disorders of pregnancy

\section{Acknowledgements}

The authors would like to thank Enago (www.enago.jp) for the English language review.

\section{Authors' contributions}

SH collected and interpreted the patient's data, collected previous reports and wrote the first draft of this paper. MS and $\mathrm{HO}$ also interpreted the data and revised the first draft. SI and HY also revised the first draft and support the data collection. All authors approved the final manuscript.

\section{Authors' information}

SH was a junior resident of the Department of Obstetrics and Gynecology, National Center for Global Health and Medicine, Tokyo, Japan at the time of this work. Now, SH belongs to the Department of Obstetrics and

Gynecology, the Jikei University School of Medicine.

\section{Funding}

All authors had no funding support related to this report.

\section{Availability of data and materials}

The datasets that support the findings about this case are available from the corresponding author, $\mathrm{SH}$, on reasonable request.

Ethics approval and consent to participate

Not applicable.

\section{Consent for publication}

Written informed consent was obtained from the patient for publication of this case report and any accompanying images. A copy of the written consent is available for review by the Editor of this journal.

\section{Competing interests}

The authors declare that they have no competing interests.

\section{Author details}

'Department of Obstetrics and Gynecology, National Center for Global Health and Medicine, 1-21-1, Toyama, Shinjuku-ku, Tokyo 162-8655, Japan. ${ }^{2}$ Division of Rheumatic Diseases, National Center for Global Health and Medicine, Tokyo, Japan.

Received: 17 November 2020 Accepted: 17 February 2021 Published online: 24 February 2021

\section{References}

1. Gerfaud-Valentin M, Jamilloux Y, Iwaz J, Sève P. Adult-onset Still's disease. Autoimmun Rev. 2014;13:708-22.

2. Yamaguchi M, Ohta A, Tsunematsu T, Kasukawa R, Mizushima Y, Kashiwagi $\mathrm{H}$, et al. Preliminary criteria for classification of adult Still's disease. J Rheumatol. 1992;19:424-30.

3. Plaçais L, Mekinian A, Bornes M, Poujol-Robert A, Bigé N, Maury E, Fain O. Adult onset Still's disease occurring during pregnancy: case-report and literature review. Semin Arthritis Rheum. 2018;47:575-7.

4. Gerfaud-Valentin M, Hot A, Huissoud C, Durieu I, Broussolle C, Seve P. Adultonset Still's disease and pregnancy: about ten cases and review of the literature. Rheumatol Int. 2014;34:867-71. 
5. Sibai BM. Diagnosis, controversies, and management of the syndrome of hemolysis, elevated liver enzymes, and low platelet count. Obstet Gynecol. 2004;103:981-91.

6. Ch'ng CL, Morgan M, Hainsworth I, Kingham JG. Prospective study of liver dysfunction in pregnancy in Southwest Wales. Gut. 2002;51:876-80.

7. Stein GH, Cantor B, Panush RS. Adult Still's disease associated with pregnancy. Arthritis Rheum. 1980;23:248-50.

8. Green J, Kanter Y, Barzilai D. Adult Still's disease associated with pregnancy. Isr J Med Sci. 1982;18:1037-9.

9. Mok MY, Lo Y, Leung PY, Lau CS. Pregnancy outcome in patients with adult onset Still's disease. J Rheumatol. 2004;31:2307-9.

10. Smith CJF, Chambers CD. Five successful pregnancies with antenatal anakinra exposure. Rheumatol Oxf Engl. 2018;57:1271-5.

11. Nakamura H, Odani T, Shimizu Y, Takeda T, Kikuchi H. Usefulness of tacrolimus for refractory adult-onset Still's disease: report of six cases. Mod Rheumatol. 2016;26:963-7.

12. Moussa M, Hassan MF. Newly diagnosed adult-onset Still's disease with pure red cell aplasia in pregnancy. Arch Gynecol Obstet. 2014;290:195-8.

13. Shimizu M, Sakakibara Y, Kawano M, Yachie A. Transient impairment of NK cell function in an infant born to a mother with adult-onset Still's disease: perinatal effect of maternal IL-18. Clin Immunol. 2012;143:273-4

14. Le Loët $X$, Daragon A, Duval C, Thomine E, Lauret P, Humbert G. Adult onset Still's disease and pregnancy. J Rheumatol. 1993;20:1158-61.

15. Parry G, Goudevenos J, Williams DO. Coronary thrombosis postpartum in a young woman with Still's disease. Clin Cardiol. 1992:15:305-7.

16. Berger $C T$, Recher M, Steiner U, Hauser TM. A patient's wish: anakinra in pregnancy. Ann Rheum Dis. 2009:68:1794-5.

17. Fischer-Betz R, Specker C, Schneider M. Successful outcome of two pregnancies in patients with adult-onset Still's disease treated with IL-1 receptor antagonist (anakinra). Clin Exp Rheumatol. 2011;29:1021-3.

18. Kaplinsky N, Pras M, Frankl O. An adult form of juvenile rheumatoid arthritis. Arch Intern Med. 1980;140:1073-4.

19. Yebra Bango M, García Paez JM, Solovera JJ, Merino MF, Girón González JA. Adult-onset Still's disease: a case with onset during pregnancy. Arthritis Rheum. 1985:28:957.

20. Falkenbach A, Lembcke B, Schneider M, Wigand R, Mulert-Ernst R, Caspary W. Polyserositis in adult Still's disease with onset during pregnancy [corrected]. Clin Rheumatol. 1994;13:513-7.

21. Mahmud T, Hughes GR. Intravenous immunoglobulin in the treatment of refractory adult Still's disease. J Rheumatol. 1999:26:2067-8.

22. Liozon E, Ly K, Aubard Y, Vidal E. Intravenous immunoglobulins for adult Still's disease and pregnancy. Rheumatol Oxf Engl. 1999:38:1024-5.

23. Yamamoto M, Tabeya T, Suzuki C, Naishiro Y, Yajima H, Shimizu Y, et al. Adult-onset Still's disease in pregnancy. Mod Rheumatol. 2012;22:163-5.

24. Lin A, Ma TP, Cheng FW, Ng PC. Neonatal haemophagocytic lymphohistiocytosis associated with maternal adult-onset Still's disease. Neonatology. 2016;110:267-9.

25. De Miguel E, Cuesta M, Martín-Mola E, Gijòn-Baños J. Adult Still's disease and pregnancy. J Rheumatol. 1992;19:498.

26. Sayarlioglu M, Sahin M, Cetin GY, Avan R, Cerit M. Maternal exposure to leflunomide and methotrexate in a patient with adult-onset Still's disease. Rheumatol Oxf Engl. 2010;49:1787-9.

27. Park JH, Kim SH, Kim HJ, Lee SJ, Jeong DC, Kim SY. Macrophage activation syn- drome in a newborn infant born to a mother with autoimmune disease. J Perinatol. 2015;35:158-60.

28. Pan VL, Haruyama AZ, Guberman C, Kitridou RC, Wing DA. Newly diagnosed adult onset still disease in pregnancy. Obstet Gynecol. 2003;101:1112-6.

29. Odai T, Isozaki T, Kasama T, Ogata H, Kinugasa E. Therapeutic efficacy of leukocytapheresis in a pregnant woman with refractory adult-onset Still's disease. Intern Med. 2015;54:2261-6.

30. Katz WE, Starz TW, Winkelstein A. Recurrence of adult Still's disease after pregnancy. J Rheumatol. 1990;17:373-4.

31. Dunn T, Cho M, Medeiros B, Logan A, Ungewickell A, Liedtke M. Hemophagocytic lymphohistiocytosis in pregnancy: a case report and review of treatment options. Hematology. 2012:17:325-8.

32. De Carolis S, Cianci F, Del Sordo G, Garofalo S, Garufi C, Lanzone A, et al. Adult onset Still's disease and pregnancy. Autoimmun Rev. 2019:18:102356.

33. Colafrancesco S, Priori R, Alessandri C, Perricone C, Pendolino M, Picarelli G, Valesini G. IL-18 serum level in adult onset Still's disease: a marker of disease activity. Int J Inflam. 2012;2012:156890.
34. Izuka S, Yamashita H, Takahashi Y, Kaneko H. Serum aldolase serves as a useful marker for diagnosis and assessment of disease activity in patients with adult-onset Still's disease. Clin Exp Rheumatol. 2020;38 Suppl 127(5):119.

35. Jamilloux Y, Gerfaud-Valentin M, Henry T, Sève P. Treatment of adult-onset Still's disease: a review. Ther Clin Risk Manag. 2015;11:33-43.

36. Buyon JP, Kim MY, Guerra MM, Laskin CA, Petri M, Lockshin MD, et al. Predictors of pregnancy outcomes in patients with lupus: a cohort study. Ann Intern Med. 2015;163:153-63.

37. Smith CJF, Förger F, Bandoli G, Chambers CD. Factors associated with preterm delivery among women with rheumatoid arthritis and women with juvenile idiopathic arthritis. Arthritis Care Res. 2019;71:1019-27.

38. Clark CA, Spitzer KA, Nadler JN, Laskin CA. Preterm deliveries in women with systemic lupus erythematosus. J Rheumatol. 2003;30:2127-32.

39. Ida A, Tsuji Y, Muranaka J, Kanazawa R, Nakata Y, Adachi S, et al. IL-18 in pregnancy; the elevation of IL-18 in maternal peripheral blood during labour and complicated pregnancies. J Reprod Immunol. 2000;47:65-74.

\section{Publisher's Note}

Springer Nature remains neutral with regard to jurisdictional claims in published maps and institutional affiliations.
Ready to submit your research? Choose BMC and benefit from:

- fast, convenient online submission

- thorough peer review by experienced researchers in your field

- rapid publication on acceptance

- support for research data, including large and complex data types

- gold Open Access which fosters wider collaboration and increased citations

- maximum visibility for your research: over $100 \mathrm{M}$ website views per year

At BMC, research is always in progress.

Learn more biomedcentral.com/submissions 